\title{
Effect of Temperature Variation on Vibration Monitoring of Prestressed Concrete Girders
}

\author{
Thanh-Canh Huynh, ${ }^{1}$ Young-Hwan Park, ${ }^{2}$ Jae-Hyung Park, ${ }^{3}$ \\ Dong-Soo Hong, ${ }^{4}$ and Jeong-Tae Kim ${ }^{1}$ \\ ${ }^{1}$ Department of Ocean Engineering, Pukyong National University, 599-1 Daeyeon-3-dong, Nam-gu, Busan 608-737, Republic of Korea \\ ${ }^{2}$ Structural Engineering Division, Korea Institute of Construction Technology, Gyeonggi-do 411-472, Republic of Korea \\ ${ }^{3}$ Department of Ocean Engineering, Pukyong National University, Busan 608-737, Republic of Korea \\ ${ }^{4}$ BT Consultant Co., Gyeonggi-do 411-472, Republic of Korea
}

Correspondence should be addressed to Jeong-Tae Kim; j0k9180@gmail.com

Received 5 September 2014; Accepted 10 November 2014

Academic Editor: Ting-Hua Yi

Copyright (C) 2015 Thanh-Canh Huynh et al. This is an open access article distributed under the Creative Commons Attribution License, which permits unrestricted use, distribution, and reproduction in any medium, provided the original work is properly cited.

\begin{abstract}
The effect of temperature variation on vibration monitoring of prestressed concrete (PSC) girders is experimentally analyzed. Firstly, vibration features such as autoregressive (AR) coefficient, correlation coefficient of power spectral density (CC of PSD), natural frequency, and mode shape are selected to estimate the effect of temperature variation on vibration characteristics of PSC girders. Secondly, vibration experiments on a lab-scale PSC girder are performed under the condition of temperature variation. Finally, the vibration features with respect to the temperature variation are analyzed to estimate the effect of temperature in vibration characteristics of the PSC girder.
\end{abstract}

\section{Introduction}

For the past decades, the interest in structural health monitoring of prestressed concrete (PSC) structures has been increased. In a variety of civil engineering structures, PSC girders are main components to resist against external loadings [1]. For a PSC girder bridge, flexural stiffness in girder and prestress force in tendon are two essential parameters that should be secured for its serviceability and safety against external loadings. Unless the PSC girder bridges are instrumented at the time of construction, the occurrence of damage cannot be directly monitored and other alternative methods should be sought.

Since as early as 1970s, many researchers have focused on the possibility of using vibration characteristics of a structure as an indication of its structural damage [2-6]. The most appealing feature associated with using vibration properties is that they are relatively simple to measure and to utilize for a prompt diagnosis. Recently, research efforts have been made to monitor the change in modal properties of the PSC structures in relation to the change in prestress forces [7], to investigate the dynamic behaviors of prestressed composite girder bridges [8], and to identify the change in prestress forces by measuring dynamic responses of prestressed beams [9-11].

However, the practicality of the so-called "bridge diagnosis via vibration monitoring" is limited for real PSC girder bridges since even significant damage sources may not be revealed as remarkable changes in vibration features due to temperature-induced uncertainty [12-17]. In a real-life situation of a PSC girder bridge, it is reasonable to say that temperature differences are about $10 \sim 20^{\circ} \mathrm{C}$ during day and night and about $20 \sim 50^{\circ} \mathrm{C}$ during a year. To account for the significant condition, therefore, temperature-induced changes in vibration properties should be accounted for the PSC girder bridge.

This study presents the effect of temperature on vibration responses of the prestressed concrete girder and also estimates the relative sensitivities of the selected vibration features. The following approaches are implemented to achieve the objective. Firstly, vibration features such as autoregressive coefficient, power spectral density, natural frequency, and mode shape are selected for estimating the effect of temperature variation on PSC girders. Secondly, experiments 
on a lab-scale PSC girder are described. The experiments are performed under the condition of temperature variation. Finally, vibration characteristics of the PSC girder are analyzed with respect to the temperature variation. Temperatureinduced effects on vibration monitoring of the PSC girder are estimated for the selected vibration features.

\section{Vibration Features for Estimation of Temperature Effect}

Vibration features selected to estimate the effect of temperature variation on the PSC girder include autoregressive model (AR model), correlation coefficient of power spectral density (CC of PSD), natural frequency, and mode shape. Once acceleration responses are measured at distributed location, the vibration features are extracted for the structure. For each type of vibration features, the effect of temperature is estimated by regression analysis.

2.1. Autoregressive Model. AR model is one of the time series analysis methods. It forecasts future responses from past time history responses. In this study, the AR model is defined in terms of acceleration responses as follows [18]:

$$
\ddot{v}(t)=\sum_{j=1}^{a} \varphi_{j} \ddot{v}(t-j)+e(t),
$$

where $\ddot{v}(t)$ is the time history of acceleration at time step $t, \varphi_{j}$ is the $j$ th AR coefficient, $a$ is the order of AR model, and $e(t)$ is the residual error. The change in AR coefficients represents the change in structural parameters.

Mahalanobis squared distance (MSD) is utilized to calculate the change of AR coefficients due to structural change. Consider

$$
D_{\zeta}=\left(\varphi_{\zeta}-\bar{\varphi}\right)^{T} S^{-1}\left(\varphi_{\zeta}-\bar{\varphi}\right)
$$

where $D_{\zeta}$ is the MSD value, $\varphi_{\zeta}$ is the AR coefficient vector (outlier), $\bar{\varphi}$ is the mean vector of $n$ sets of AR coefficient, and $S$ is the covariance matrix of $n$ sets of AR coefficient. The variation of MSD indicates the variation of AR coefficients due to structural change. The number of set, $n$, is determined by partial autocorrelation function of the first acceleration sample in intact state. It is noted that the number of set should be larger than the order of AR model.

2.2. Correlation Coefficient of Power Spectral Density. Assume there are two acceleration signals, $x(t)$ and $y(t)$, measured before and after structural change, respectively. The corresponding power spectral densities, $S_{x x}$ and $S_{y y}$, are calculated from Welch's procedure as [18]

$$
\begin{aligned}
& S_{x x}(f)=\frac{1}{n_{d} T} \sum_{i=1}^{n_{d}}\left|X_{i}(f, T)\right|^{2}, \\
& S_{y y}(f)=\frac{1}{n_{d} T} \sum_{i=1}^{n_{d}}\left|Y_{i}(f, T)\right|^{2},
\end{aligned}
$$

where $X$ and $Y$ are the frequency response transformed from correspondent acceleration signal; $n_{d}$ is the number of divided segments; and $T$ is the data length of divided segment.

The correlation coefficient (CC) of PSDs represents the linear identity between the two PSDs obtained before and after structural change, as follows:

$$
\rho_{X Y}=\frac{E\left[S_{x x} S_{y y}\right]-\mu_{S_{x x}} \mu_{S_{y y}}}{\sigma_{S_{x x}} \sigma_{S_{y y}}},
$$

where $E[\cdot]$ is the expectation operator and $\sigma_{S_{x x}}$ and $\sigma_{S_{y y}}$ are the standard deviations of PSDs of acceleration signals measured before and after structural change, respectively. If any structural change occurs in target structure, its acceleration responses would be affected and, consequently, the decrement of CC can be a warning sign for the presence of the special cause in the structure.

For estimating CC of PSDs due to temperature variation, the excitation force should be consistently maintained during experiments. In the lab-scale experiment, the impact testing can be easily maintained to be consistent. However, the excitation magnitude can be different for each testing in the full-scale civil engineering structures. For such cases, the vibration responses should be normalized according to the excitation magnitude. In addition, the ambient vibration data seems to be difficult to apply as the input excitation varies over time, which results in different CC of PSDs although the temperature remains the same.

2.3. Modal Parameters. Frequency domain decomposition (FDD) method $[19,20]$ is used to extract modal parameters such as natural frequency and mode shape. The singular values of the PSD function matrix $\mathbf{S}(\omega)$ are used to estimate the natural frequencies instead of the PSD functions themselves as follows [20]:

$$
\mathbf{S}(\omega)=\mathbf{U}(\omega)^{T} \boldsymbol{\Sigma}(\omega) \mathbf{V}(\omega),
$$

where $\Sigma$ is the diagonal matrix consisting of the singular values, $\sigma_{i}$ 's $(i=1, \ldots, N)$, and $\mathbf{U}$ and $\mathbf{V}$ are unitary matrices. Since $\mathbf{S}(\omega)$ is symmetric, $\mathbf{U}$ becomes equal to $\mathbf{V}$. In this FDD method, the natural frequencies can be determined from the peak frequencies of the singular value and the mode shape from anyone of the column vectors of $\mathbf{U}(\omega)$ at the corresponding peak frequencies. In this study, the first singular value $\sigma_{1}(\omega)$ is used to estimate the modal parameters.

Mode shapes measured before and after structural change are examined by modal assurance criterion (MAC). The MAC provides a measure of the least squares deviation or scatter of the points from the linear correlation

$$
\operatorname{MAC}\left(\phi_{i}, \phi_{i}^{*}\right)=\frac{\left[\phi_{i}^{T} \phi_{i}^{*}\right]^{2}}{\left[\phi_{i}^{T} \phi_{i}\right]\left[\phi_{i}^{* T} \phi_{i}^{*}\right]},
$$

where $\phi_{i}$ and $\phi_{i}^{*}$ are the modal vectors which are extracted from acceleration signals measured before and after structural change, respectively. The MAC value provides quantifying of the comparison between the two sets of mode shape data. In practice, a value of MAC close to the unity is expected 


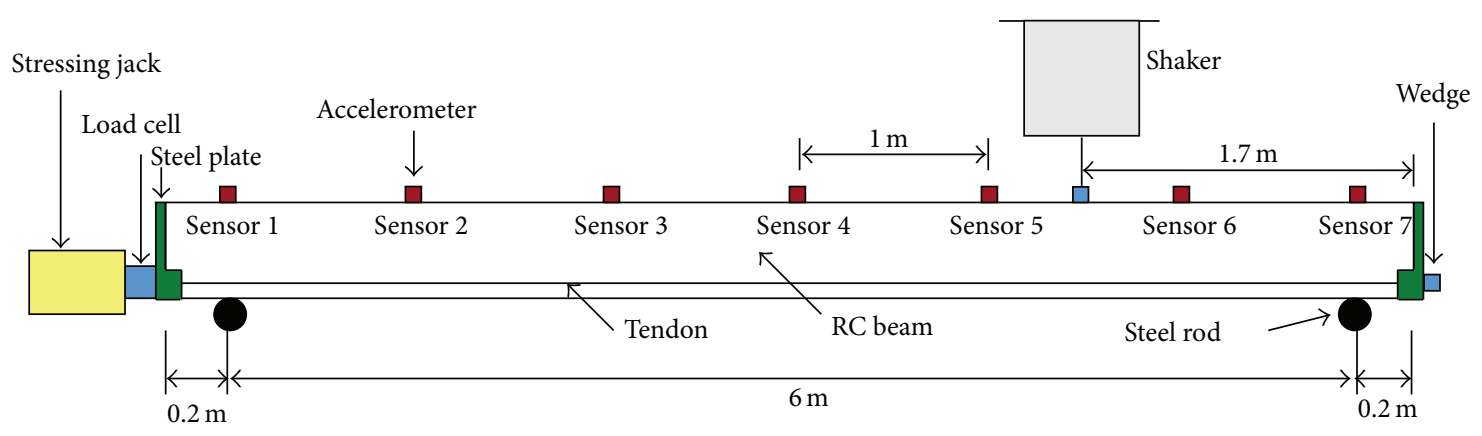

(a) Test setup

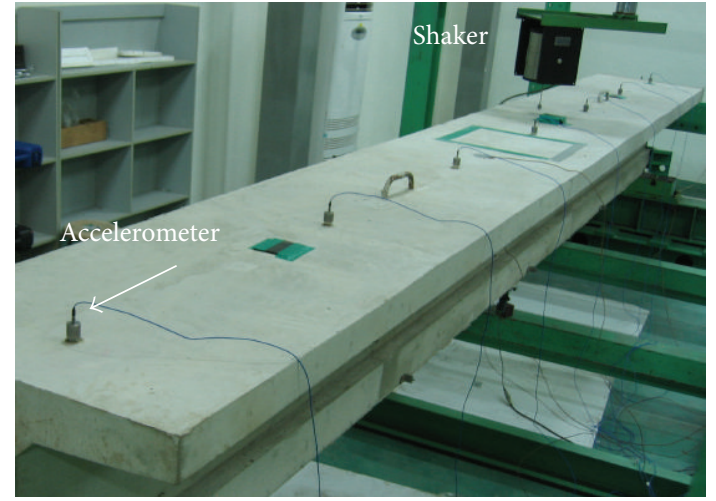

(b) Test girder

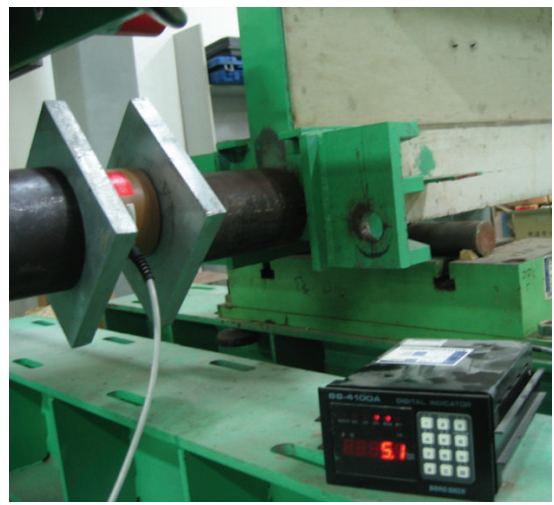

(c) Prestress force control

FIGURE 1: Vibration tests on PSC girder.

if the two sets of mode shapes have no differences caused by structural change; otherwise, the MAC value would decrease. This method can be utilized to obtain the information on what vibration modes are more sensitive to the structural change.

2.4. Regression Analysis. Regression analysis gives the information on the relationship between a response variable and one or more independent variables. From regression analysis, the response variable is expressed as a function of the predictor variables. The relationship obtained from regression analysis can be used to predict values of the response variable and identify variables that most affect the response. The value of each predictor variable can be accessed through statistical tests on the estimated coefficients of the predictor variables.

An example of a regression model is the simple linear regression model which is a linear relationship between response variable $(\mathrm{RV})$ and the predictor variable $(T)$ of the form

$$
\mathrm{RV}=a+b T
$$

in which $a$ and $b$ are regression coefficients which are unknown modal parameters. In this study, the response variables are MSD of AR coefficient (2), CC of PSDs (3), and natural frequency and mode shape calculated by (6). Also, the predictor variable $T$ is temperature measured from the experiment. The error term has to be equal to zero on average. In statistics, simple linear regression is the least squares estimator of a linear regression model with a single predictor variable. Simple linear regression fits a straight line through the set of $n$ points in such a way that makes the sum of squared residuals of the model (i.e., vertical distances between the points of the data set and the fitted line) as small as possible.

\section{Experiments on PSC Girder}

As illustrated in Figure 1, dynamic tests were performed on a lab-scaled PSC girder. While room temperatures were handled to vary in the range of about $5 \sim 23^{\circ} \mathrm{C}$, a set of prestress cases were simulated to the PSC girder from which vibration responses were measured to determine vibration features and modal parameters. In this study, vibration features of interest include autoregressive coefficient and power spectral density. Also, modal parameters of interest are natural frequencies and mode shape. Note that damping properties of the PSC girder are not dealt with due to the difficulties in measurement and interpretation.

The PSC girder was simply supported and installed on a rigid testing frame. Two simple supports were modeled by steel rods between the girder and the rigid frame. As detailed in existing publications [21], the PSC girder model has the T-section reinforced in both longitudinal and transverse direction with $10 \mathrm{~mm}$ diameter reinforcing bars. As the prestressing tendon, a seven-wire monostrand with $15.2 \mathrm{~mm}$ 


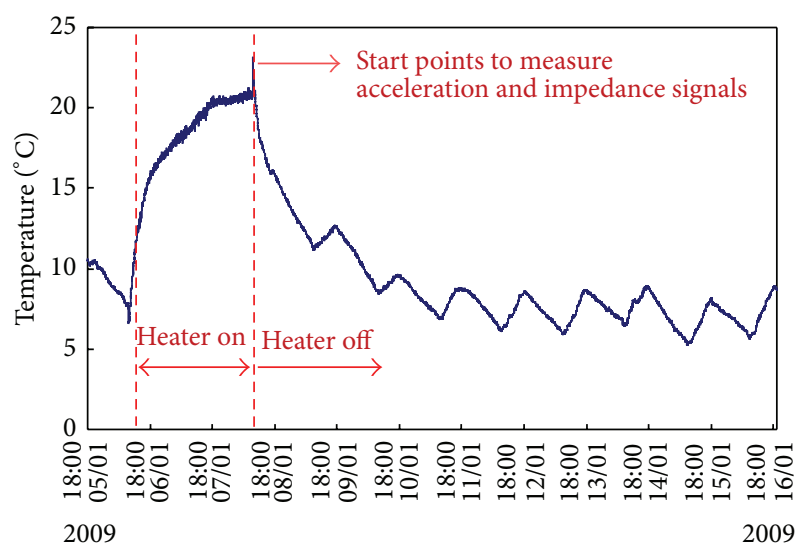

FIgURE 2: Time history of temperature during experiments.

diameter was embedded in a $25 \mathrm{~mm}$ diameter duct. During the tests, the prestress force was fixed as $98.0 \mathrm{kN}$.

Seven accelerometers noted as Sensors 1-7 in Figure 1(a) were placed in the girder with a constant $1 \mathrm{~m}$ interval. The impact excitation was applied in vertical direction by an electromagnetic shaker VTS100 at a location $1.7 \mathrm{~m}$ distanced from the right edge. The impact magnitude of the impact testing was consistently maintained during the experimental tests. Each accelerometer (PCB 393B04) has nominal sensitivity of $1 \mathrm{~V} / \mathrm{g}$ and specified frequency range $( \pm 5 \%)$ of $0.06-450 \mathrm{~Hz}$. The sampling frequency of $500 \mathrm{~Hz}$ was used to measure dynamic responses. The data acquisition system consists of a 16-channel PXI-4472 DAQ, a NI controller with LabVIEW, and MATLAB software. Temperature data were measured by using K-type thermocouple wires and KYOWA (EDX-100A) Dynamic Logger.

A series of tests were performed for 9 consecutive days. Figure 2 shows time history of room temperature during the test period. During the tests on the PSC girder, temperatures varied between $5^{\circ} \mathrm{C}$ and $23^{\circ} \mathrm{C}$. Humidity in the laboratory was kept close to $40 \sim 45 \%$ in order to minimize the effect of humidity variation on the vibration characteristics. Temperature was controlled as designed for the tests by air conditioners and heaters (e.g., heater on and off). Vibration tests started at 18:00 hour of January 8 as the laboratory temperature reached up to $23^{\circ} \mathrm{C}$. Then the room temperature was controlled to be decreased gradually for the remaining days. It is noted that the room temperature changed day and night.

\section{Temperature Effect on Vibration Features of PSC Girder}

4.1. AR Model. As the first vibration feature, AR model is used to estimate temperature effects on vibration characteristics of the PSC girder. The overall steps are as follows: firstly, a set of vibration responses are measured for various temperatures from the reference PSC girder; secondly, vibration features are extracted for the temperature variation by computing AR coefficient (1) and MSD (2); thirdly, time histories of temperature and MSD values are analyzed; finally, regression analysis is performed by fitting (8) to estimate the linear relationship between temperature variation and the extracted AR features.

As the first step, acceleration responses were measured from the PSC girder. Figure 3(a) shows the acceleration signals measured from Sensor 5. For temperature $22.5^{\circ} \mathrm{C}$, 2048 acceleration data were sampled for 4 seconds by a single impulse excitation. As the second step, AR features were extracted from the measured acceleration signals. Figure 3(b) shows partial autocorrelation data for the acceleration signals of Sensor 5, from which the order of AR model was decided as 50. Using the decided order 50, AR coefficients for all acceleration signals measured from Sensor 5 were estimated for temperatures $5.4^{\circ} \mathrm{C} 22.5^{\circ} \mathrm{C}$, as shown in Figure 3(c).

As the final step, the linear regression between temperature variation and AR coefficients was analyzed by the use of MSDs of AR coefficients. Figure 4(a) shows the time history for MSDs of AR coefficients calculated for temperatures $5.4^{\circ} \mathrm{C} 22.5^{\circ} \mathrm{C}$. Figure $4(\mathrm{~b})$ shows the linear relationship between the temperatures and the MSDs of AR coefficients. The empirical equation of the MSD as a function of temperature $(T)$ is as follows:

$$
\mathrm{MSD}=-3283 T+74569
$$

in which the MSD value changes as 3283 when temperature (T) changes by $1^{\circ} \mathrm{C}$. It is noted that the correlation level was low. It is also noted that the AR model provided less consistent but rather poor estimation of the temperature effect on the vibration characteristics of the PSC girder. It is also noted that the quality of the AR model was dependent upon the amount of sampled data and the type of excitation sources.

4.2. CC of PSD. As the second feature, CC of PSDs was selected to estimate temperature effect on vibration characteristics of the PSC girder. The overall steps are as follows: firstly, acceleration data and temperature data are measured from selected distributed locations; secondly, CC of PSDs (3) and LCL (5) are computed for feature extraction; thirdly, time histories of temperature and CC of PSDs values are analyzed; and finally, a linear regression is estimated by fitting (8) for the relationship between temperature variation and the CC of PSDs.

For temperatures $5.4^{\circ} \mathrm{C} \sim 22.5^{\circ} \mathrm{C}$, as shown in Figure 5(a), PSDs were extracted from the acceleration signals of Sensor 5, at which 2048 acceleration data were sampled for 4 seconds by a single impulse excitation. As shown in Figure 5(b), CC of PSDs were computed for temperatures $5.4^{\circ} \mathrm{C} \sim 22.5^{\circ} \mathrm{C}$ by using PSDs at the maximum $22.5^{\circ} \mathrm{C}$ as the reference. It is observed that CC of PSDs varies along with the variation of room temperature. Figure 5(c) shows the linear regression between the temperatures and the CC of PSDs. The empirical equation of the CC of PSDs as a function of temperature $(T)$ is as follows:

$$
\mathrm{CC}=0.019 T+0.676
$$

in which the CC of PSDs changes as 0.019 when temperature (T) changes by $1^{\circ} \mathrm{C}$. It is noted that the correlation level was relatively moderate according to Dancey and Reidy's 


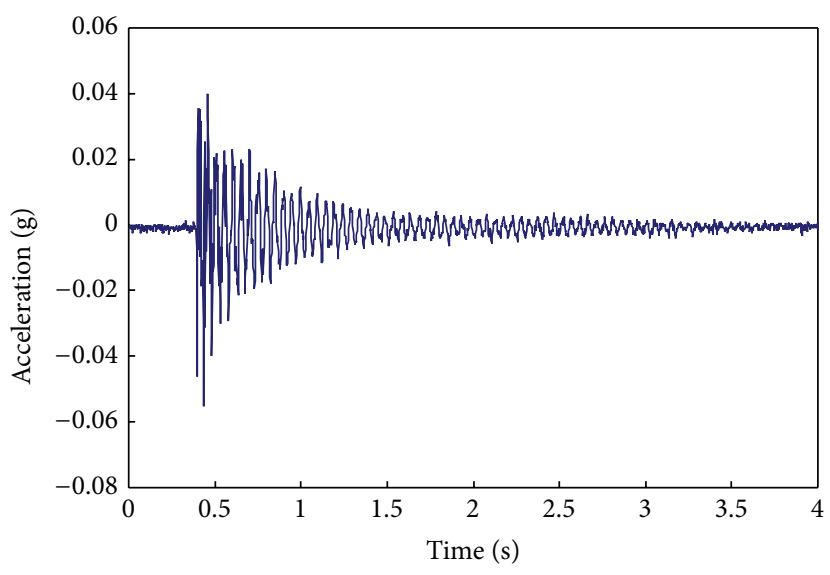

(a) Acceleration signal of Sensor 5: temperature $22.5^{\circ} \mathrm{C}$

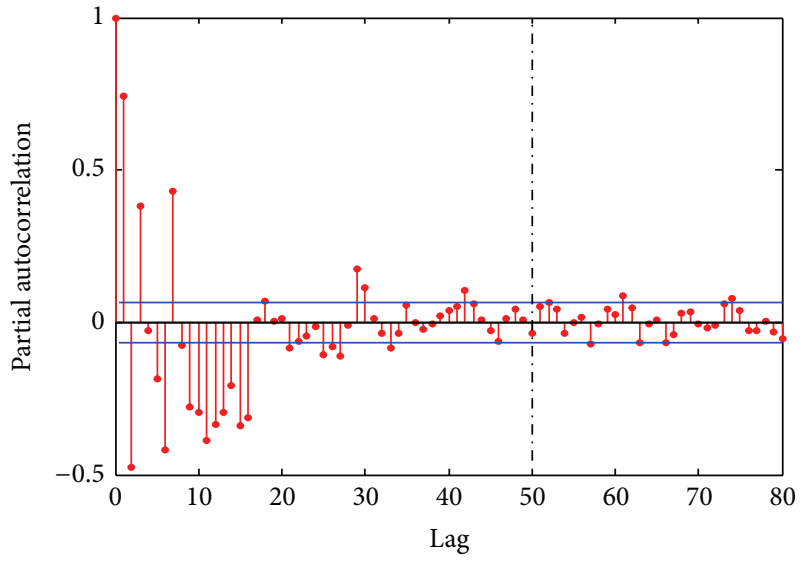

(b) Partial autocorrelation of Sensor 5: temperature $22.5^{\circ} \mathrm{C}$

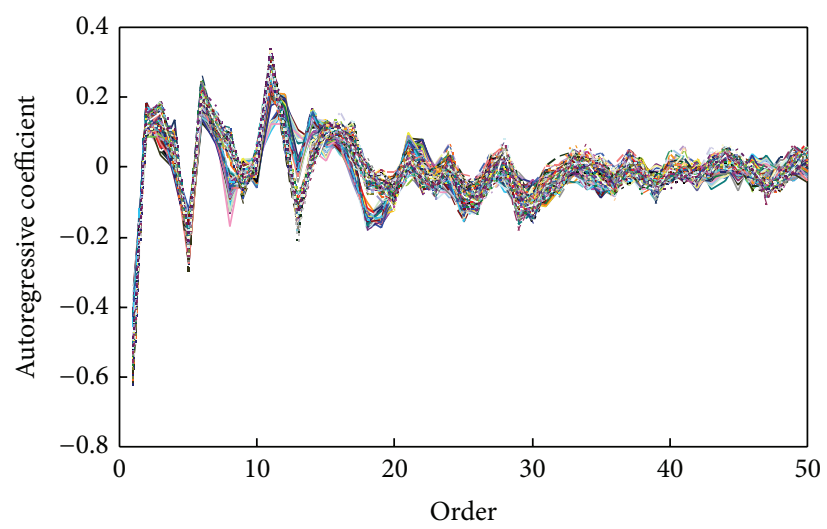

(c) $\mathrm{AR}$ coefficient of Sensor 5: temperatures $5.4^{\circ} \mathrm{C}$ to $22.5^{\circ} \mathrm{C}$

FIgURE 3: Acceleration signals and AR coefficients for estimation of AR model.

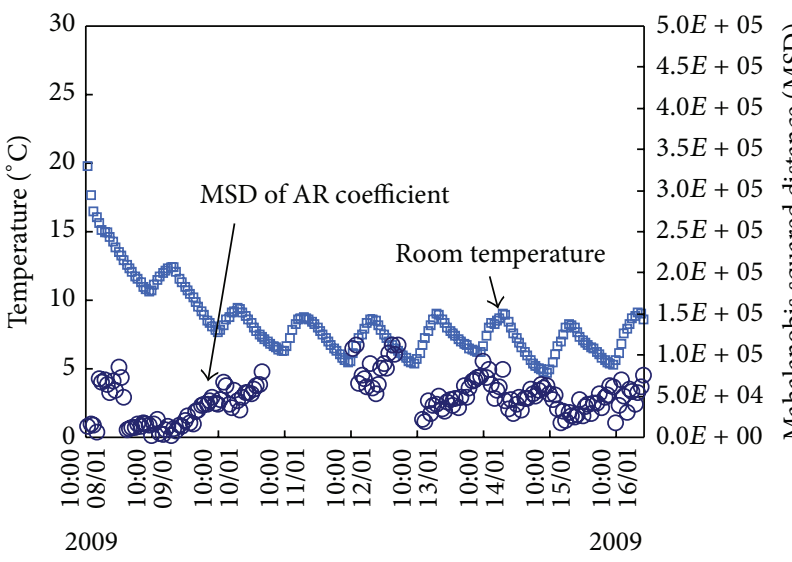

(a) Time history of MSD of AR coefficient

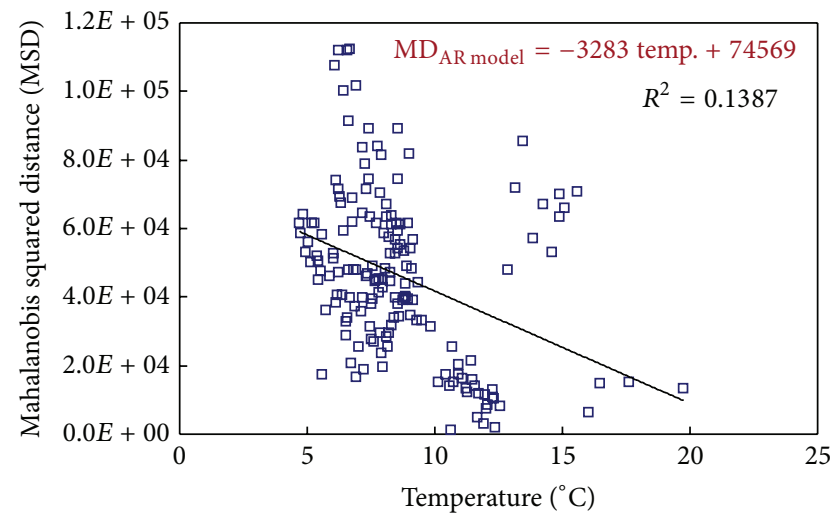

(b) Temperature versus MSD of AR model

FIGURE 4: Linear regression analysis result for acceleration-based AR model.

categorization [22]. However, the CC of PSDs gave relatively consistent estimation of the temperature effect on the vibration characteristics of the PSC girder.

4.3. Natural Frequency. Next, temperature effect on vibration feature is estimated by natural frequency of the PSC girder.
The overall steps are as follows: first, acceleration data and temperature data are measured from selected distributed locations; secondly, from the FDD method defined as (6), natural frequencies were estimated by the singular values of the PSD function matrix $\mathbf{S}(\omega)$; thirdly, time histories of temperature and natural frequencies are analyzed; and finally, 


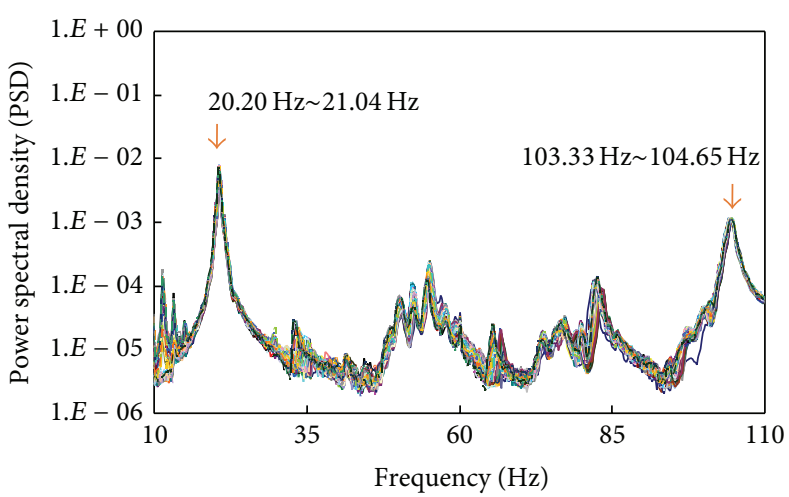

(a) PSDs at $5.4^{\circ} \mathrm{C} \sim 22.5^{\circ} \mathrm{C}$

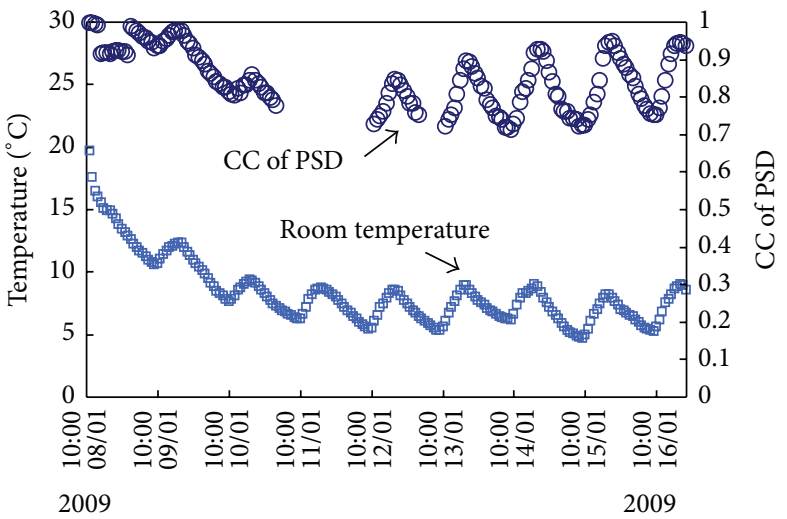

(b) Time history of CC of PSD

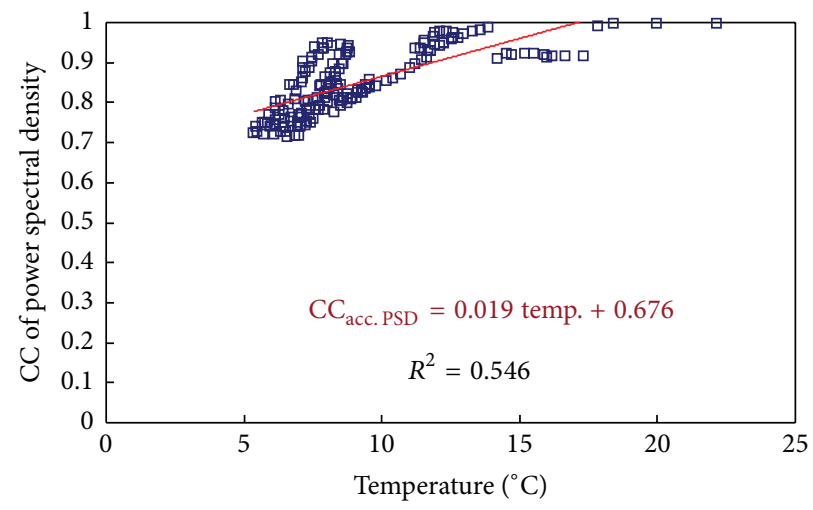

(c) Temperature versus CC of PSD

FIGURE 5: Linear regression analysis for correlation coefficient of power spectral density.

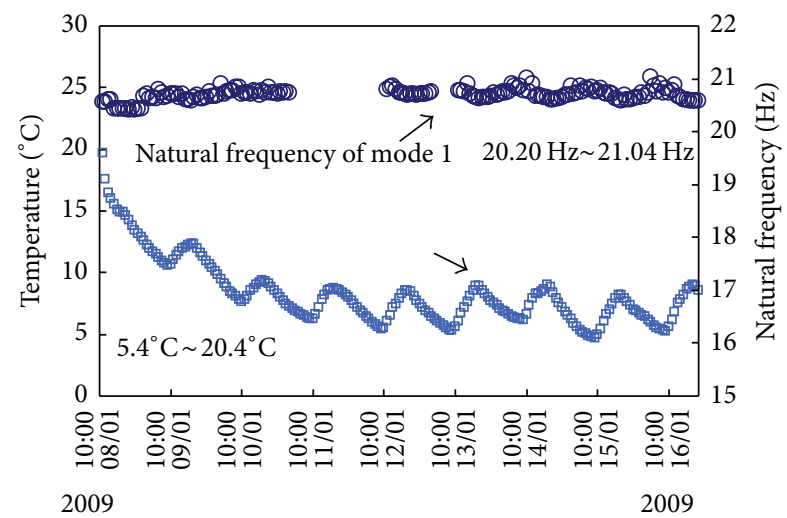

(a) Mode 1

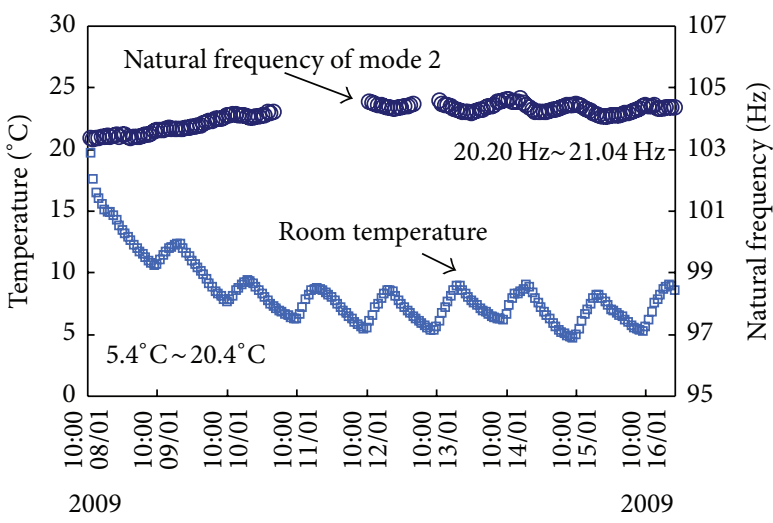

(b) Mode 2

FIGURE 6: Time history of temperature for natural frequencies.

a linear regression is estimated for the relationship between temperature variation and the extracted natural frequencies.

Acceleration signals of Sensors 1-7 were utilized for the modal extraction. From each sensor, 2048 acceleration data were sampled for 4 seconds by a single impulse excitation. Figure 6 shows time histories of temperatures and natural frequencies of the first two modes of the PSC girder. Natural frequencies of the two modes were extracted as temperatures varied between $5.4^{\circ} \mathrm{C}$ and $20.4^{\circ} \mathrm{C}$. In mode 1 , changes in natural frequencies were very small as temperatures varied up to $15^{\circ} \mathrm{C}$, as shown in Figure 6(a). In mode 2, however, changes in natural frequencies were relatively high due to the temperature variation, as shown in Figure 6(b).

From regression analysis, linear relationships between the two modes' natural frequencies and temperatures were estimated as shown in Figure 7. For the two modes, the empirical 


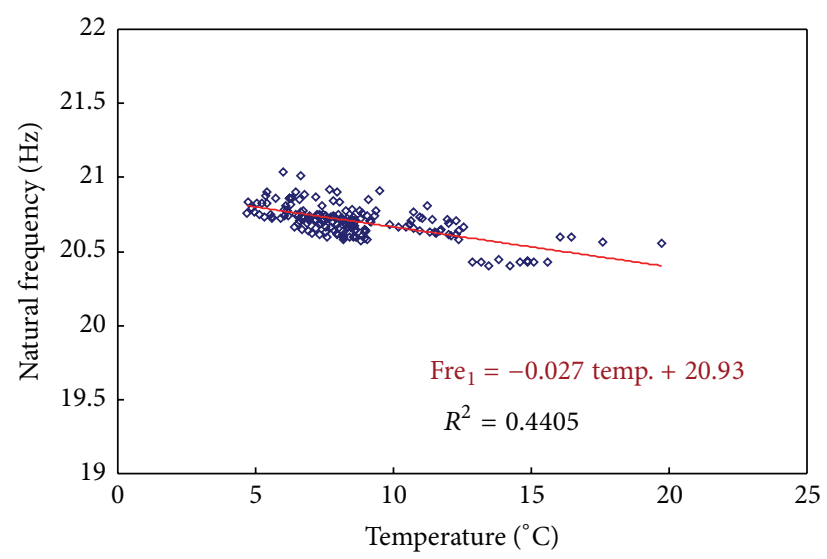

(a) Mode 1

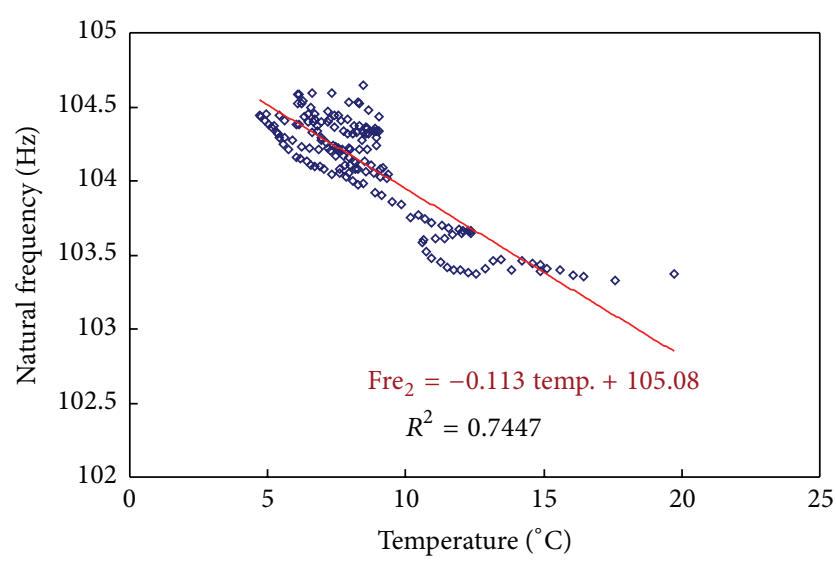

(b) Mode 2

FIGURE 7: Linear relationship between temperature and natural frequencies.

equations of the natural frequencies as a function of temperature $(T)$ are, respectively, as follows:

$$
\begin{aligned}
& \text { Freq }_{1}=-0.027 T+20.93, \\
& \text { Freq }_{2}=-0.113 T+105.08
\end{aligned}
$$

in which the first mode's natural frequencies (Freq ${ }_{1}$ ) decrease as 0.027 as temperature $(T)$ increases by $1^{\circ} \mathrm{C}$; and the second mode's natural frequencies $\left(\right.$ Freq $\left._{2}\right)$ decrease as 0.113 as temperature $(T)$ increases by $1^{\circ} \mathrm{C}$. It is noted that the correlation levels were relatively moderate for mode 1 but relatively strong for mode 2 [22]. It is also noted that natural frequencies gave relatively consistent estimation of the temperature effect on the vibration characteristics of the PSC girder.

4.4. Mode Shape. Next, temperature effect on vibration feature is estimated by mode shapes of the PSC girder. The overall steps are as follows: first, acceleration data and temperature data are measured from selected distributed locations; secondly, mode shapes were estimated by the singular values of the PSD function matrix $\mathbf{S}(\omega)$ from the FDD method (6); thirdly, MAC values are calculated by (7); fourthly, time histories of temperature and MAC values are analyzed; and finally, a linear regression is estimated for the relationship between temperature variation and the MAC values.

The same sets of acceleration signals and temperature signals as used for the analysis of natural frequencies were utilized for the analysis of mode shapes. Figure 8 shows mode shapes of the PSC girder measured by Sensors 1-7 as temperatures varies between $5.4^{\circ} \mathrm{C}$ and $22.5^{\circ} \mathrm{C}$. It is observed that overall changes in mode shapes due to temperature variation look small in both mode 1 and mode 2. Figure 9 shows time histories of temperatures and mode shapes of the first two modes. In mode 1 , the change in mode shape was very small as temperatures varied up to $15^{\circ}$. In mode 2 , however, the change in mode shape was relatively high due to the temperature variation.

From regression analysis, linear relationships between the two mode shapes and temperatures were estimated as shown in Figure 10. For the two modes, the empirical equations of the mode shapes as a function of temperature $(T)$ are, respectively, as follows:

$$
\begin{aligned}
\mathrm{MAC}_{1} & =-0.00002 T+0.9999 \\
\mathrm{MAC}_{2} & =-0.0002 T+0.9976
\end{aligned}
$$

in which the first mode's modal assurance criterion $\left(\mathrm{MAC}_{1}\right)$ almost does not change as temperature $(T)$ changes; but the second mode's modal assurance criterion $\left(\mathrm{MAC}_{2}\right)$ changes as 0.0002 as temperature $(T)$ increases by $1^{\circ} \mathrm{C}$. It is noted that the correlation levels were relatively weak in mode 1 but relatively moderate in mode 2 [22]. It is also noted that modal assurance criteria of the two modes $\left(\mathrm{MAC}_{1}\right.$ and $\left.\mathrm{MAC}_{2}\right)$ gave relatively consistent estimation of the temperature effect on the vibration characteristics of the PSC girder.

\section{Summary and Conclusion}

In this paper, the effect of temperature variation on vibration monitoring of prestressed concrete (PSC) girders was experimentally analyzed. Firstly, vibration features such as autoregressive (AR) coefficient, correlation coefficient of power spectral density (CC of PSD), natural frequency, and mode shape were selected to estimate the effect of temperature variation on PSC girders. Secondly, vibration experiments on a lab-scale PSC girder were performed under the condition of temperature variation. Finally, the selected vibration features were analyzed to estimate temperature-induced effects on vibration monitoring of the PSC girder.

Major results from the analysis on the four vibration features with respect to temperature variation are summarized as follows. Firstly, the AR model produced rather poor estimation of the temperature effect on the vibration characteristics of the PSC girder. Secondly, the CC of PSD gave relatively consistent estimation of the temperature effect on the vibration characteristics of the PSC girder. However, its correlation level of the linear regression analysis was relatively moderate. Thirdly, the natural frequencies produced 


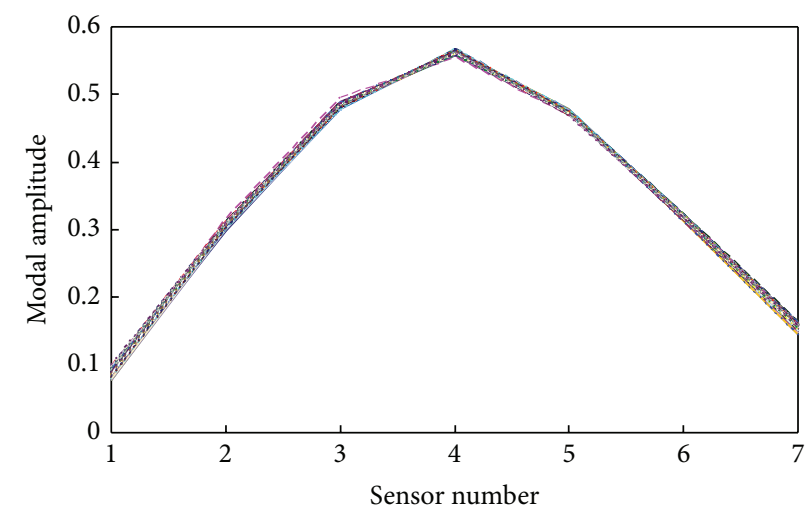

(a) Mode 1: $20.20 \mathrm{~Hz}-21.04 \mathrm{~Hz}$

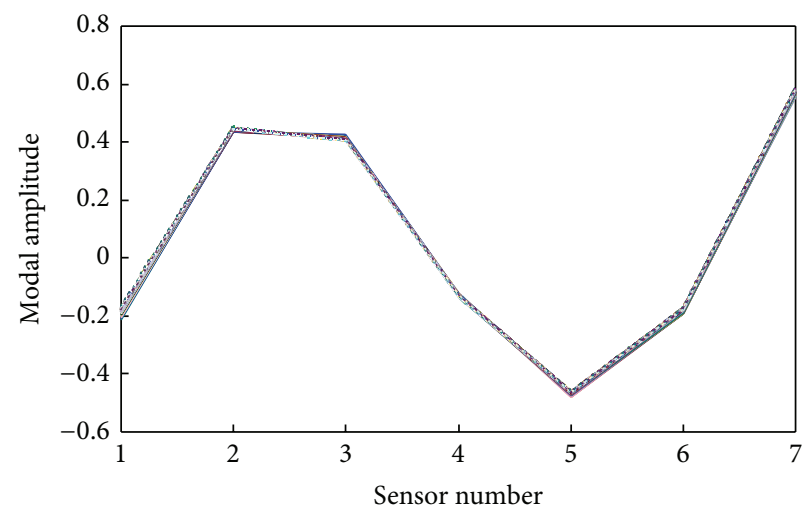

(b) Mode 2: $103.33 \mathrm{~Hz}-104.65 \mathrm{~Hz}$

Figure 8: Natural frequency and mode shape on temperature conditions for PSC girder: prestress force $98 \mathrm{kN}$, temperatures $5.4^{\circ} \mathrm{C}-22.5^{\circ} \mathrm{C}$.

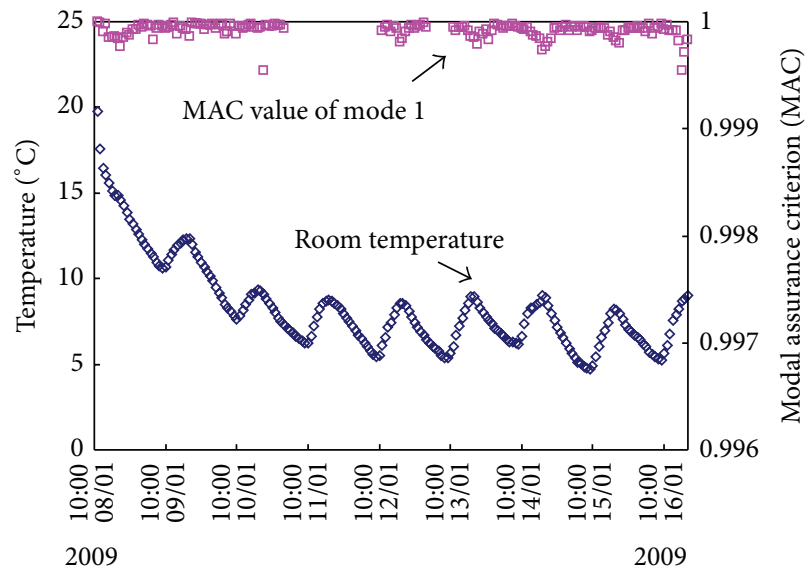

(a) Mode 1

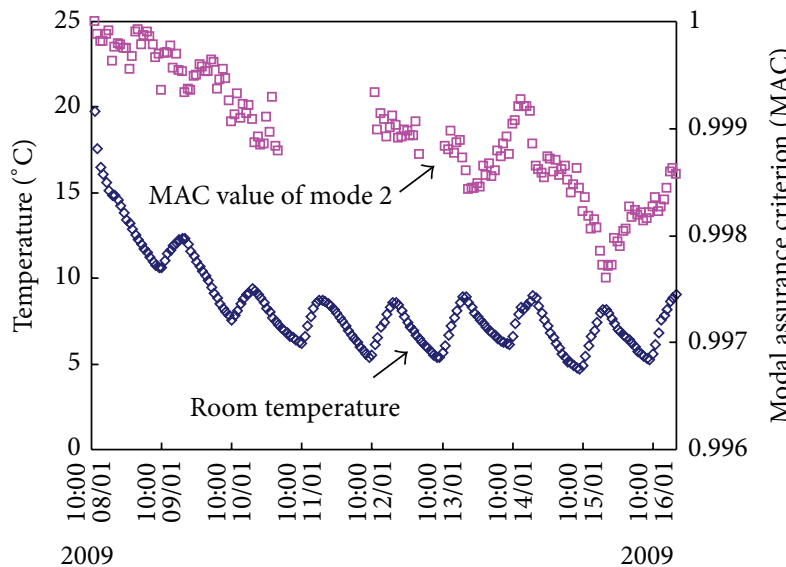

(b) Mode 2

FIGURE 9: Time history of temperature for mode shapes of PSC girder.

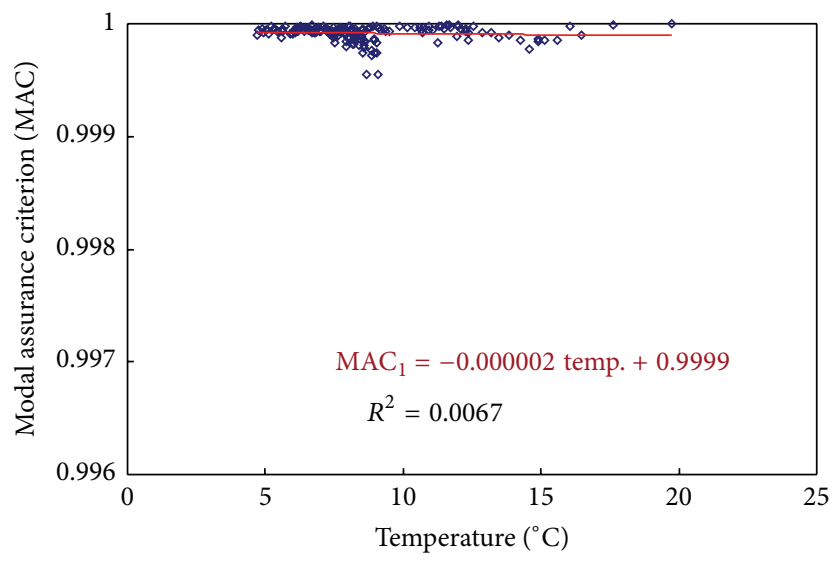

(a) Mode 1

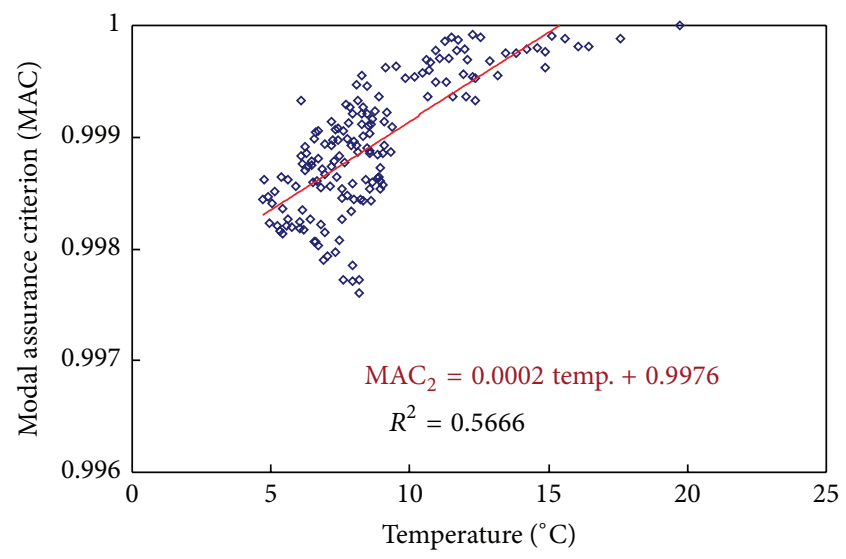

(b) Mode 2

FIGURE 10: Linear relationship between temperature and mode shapes. 
relatively consistent estimation of the temperature effect on the vibration characteristics of the PSC girder. For the natural frequencies, the correlation levels of the linear regression analysis were relatively moderate in mode 1 but relatively strong in mode 2. Finally, modal assurance criteria of the first two modes gave relatively consistent estimation of the temperature effect on the vibration characteristics of the PSC girder. For the mode shapes, the correlation levels of the linear regression analysis were relatively weak in mode 1 but relatively moderate in mode 2 . From the comparative analyses, it can be said that the natural frequency is highly correlated with temperature.

\section{Conflict of Interests}

The authors declare that there is no conflict of interests regarding the publication of this paper.

\section{Acknowledgments}

This research was supported by a grant from a strategic research project (Development of Smart Prestressing and Monitoring Technologies for Prestressed Concrete Bridges) funded by the Korea Institute of Construction Technology. Graduate students involved in this research were also partially supported by the Brain Korea 21 Plus program of Korean Government.

\section{References}

[1] E. G. Nawy, Prestressed Concrete-A Fundamental Approach, Prentice Hall, New York, NY, USA, 1996.

[2] R. D. Adams, P. Cawley, C. J. Pye, and B. J. Stone, "A vibration technique for non-destructively assessing the integrity of structures," Journal of Mechanical Engineering Science, vol. 20, no. 2, pp. 93-100, 1978.

[3] N. Stubbs and R. Osegueda, "Global non-destructive damage evaluation in solids," The International Journal of Analytical and Experimental Modal Analysis, vol. 5, no. 2, pp. 67-79, 1990.

[4] J. T. Kim and N. Stubbs, "Model-uncertainty impact and damage-detection accuracy in plate girder," Journal of Structural Engineering, vol. 121, no. 10, pp. 1409-1417, 1995.

[5] S. W. Doebling, C. R. Farrar, and M. B. Prime, "A summary review of vibration-based damage identification methods," Shock and Vibration Digest, vol. 30, no. 2, pp. 91-105, 1998.

[6] J.-T. Kim, Y.-S. Ryu, H.-M. Cho, and N. Stubbs, "Damage identification in beam-type structures: frequency-based method vs mode-shape-based method," Engineering Structures, vol. 25, no. 1, pp. 57-67, 2003.

[7] M. Saiidi, B. Douglas, and S. Feng, "Prestress force effect on vibration frequency of concrete bridges," Journal of Structure Engineering, vol. 120, no. 7, pp. 2233-2241, 1994.

[8] A. Miyamoto, K. Tei, H. Nakamura, and J. W. Bull, "Behavior of prestressed beam strengthened with external tendons," Journal of Structural Engineering, vol. 126, no. 9, pp. 1033-1044, 2000.

[9] J.-T. Kim, C.-B. Yun, Y.-S. Ryu, and H.-M. Cho, "Identification of prestress-loss in PSC beams using modal information," Structural Engineering and Mechanics, vol. 17, no. 3-4, pp. 467482, 2004.
[10] S. S. Law and Z. R. Lu, "Time domain responses of a prestressed beam and prestress identification," Journal of Sound and Vibration, vol. 288, no. 4-5, pp. 1011-1025, 2005.

[11] O. Huth, G. Feltrin, J. Maeck, N. Kilic, and M. Motavalli, "Damage identification using modal data: experiences on a prestressed concrete bridge," Journal of Structural Engineering, vol. 131, no. 12, pp. 1898-1910, 2005.

[12] M. A. Wahab and G. de Roeck, "Effect of temperature on dynamic system parameters of a highway bridge," Structural Engineering International, vol. 7, no. 4, pp. 266-270, 1997.

[13] H. Sohn, M. Dzwonczyk, E. G. Straser, A. S. Kiremidjian, K. Law, and T. Meng, "An experimental study of temperature effect on modal parameters of the Alamosa Canyon Bridge," Earthquake Engineering and Structural Dynamics, vol. 28, no. 7-8, pp. 879-897, 1999.

[14] C. R. Farrar, P. J. Cornwell, S. W. Doebling et al., "Structural health monitoring studies of the Alamosa Canyon and I-40 bridges," Los Alamos National Laboratory Report LA-13635MS, 2000.

[15] J. T. Kim, C. B. Yun, and J. H. Yi, "Temperature effects on frequency-based damage detection in plate-girder bridges," KSCE, vol. 7, no. 6, pp. 725-733, 2003.

[16] Y. Q. Ni, X. G. Hua, K. Q. Fan, and J. M. Ko, "Correlating modal properties with temperature using long-term monitoring data and support vector machine technique," Engineering Structures, vol. 27, no. 12, pp. 1762-1773, 2005.

[17] D.-S. Hong, K.-D. Nguyen, I.-C. Lee, and J.-T. Kim, “Temperature-compensated damage monitoring by using wireless acceleration-impedance sensor nodes in steel girder connection," International Journal of Distributed Sensor Networks, vol. 2012, Article ID 167120, 12 pages, 2012.

[18] J. S. Bendat and A. G. Piersol, Engineering Applications of Correlation and Spectral Analysis, Wiley-Interscience, New York, NY, USA, 2003.

[19] D. Otte, P. V. de Ponseele, and J. Leuridan, "Operational shapes estimation as a function of dynamic loads," in Proceedings of the 8th International Modal Analysis Conference, Florida, Fla, USA, January 1990.

[20] J.-H. Yi and C.-B. Yun, "Comparative study on modal identification methods using output-only information," Structural Engineering and Mechanics, vol. 17, no. 3-4, pp. 445-466, 2004.

[21] D.-D. Ho, J.-T. Kim, N. Stubbs, and W.-S. Park, "Prestress-force estimation in PSC girder using modal parameters and system identification," Advances in Structural Engineering, vol. 15, no. 6, pp. 997-1012, 2012.

[22] C. P. Dancey and J. Reidy, Statistics without Maths for Psychology, Prentice Hall, 2004. 

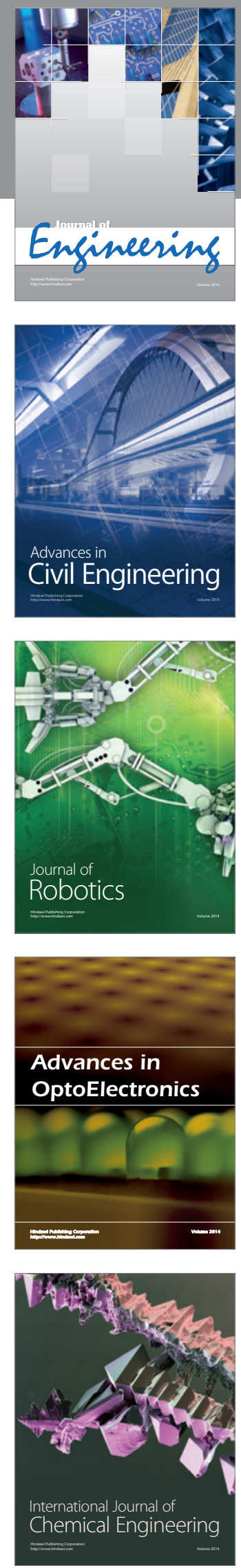

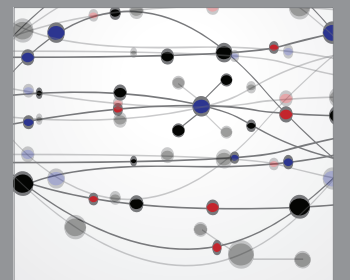

The Scientific World Journal
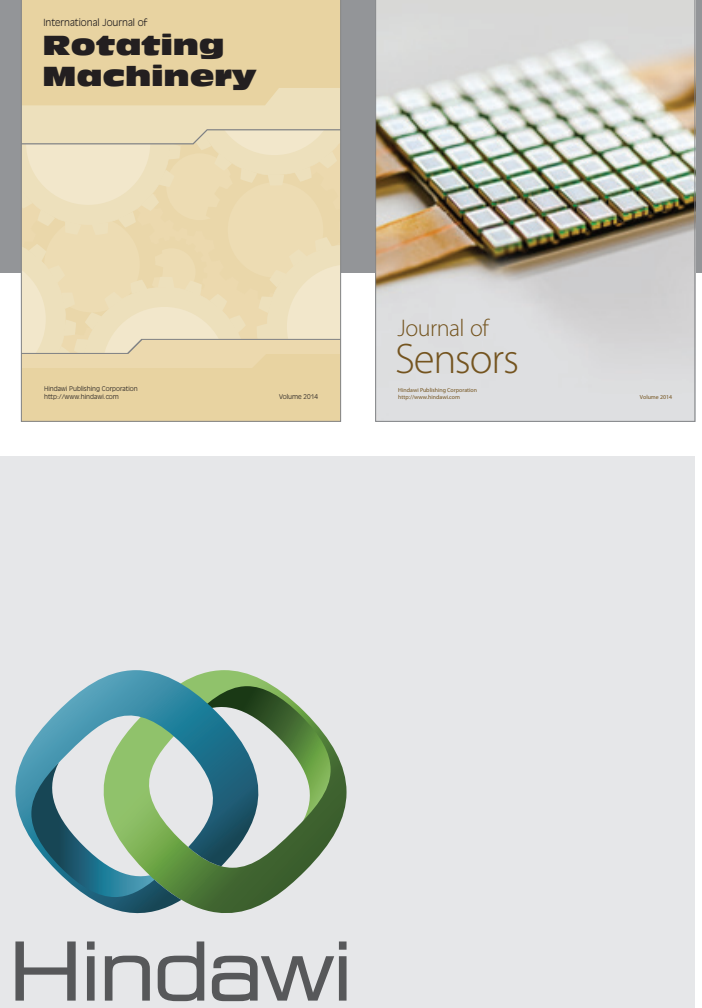

Submit your manuscripts at http://www.hindawi.com
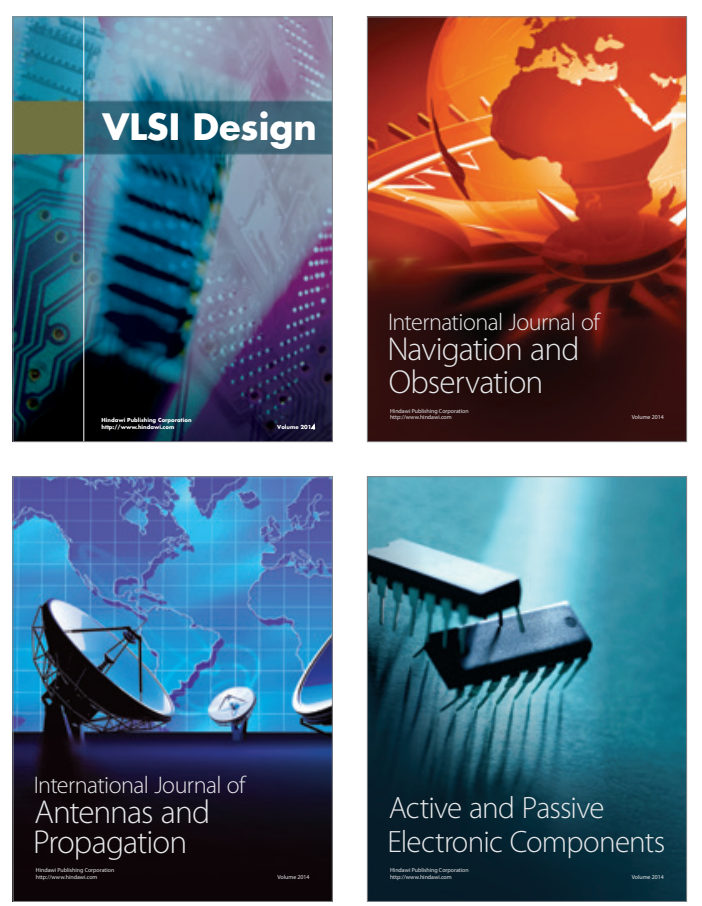
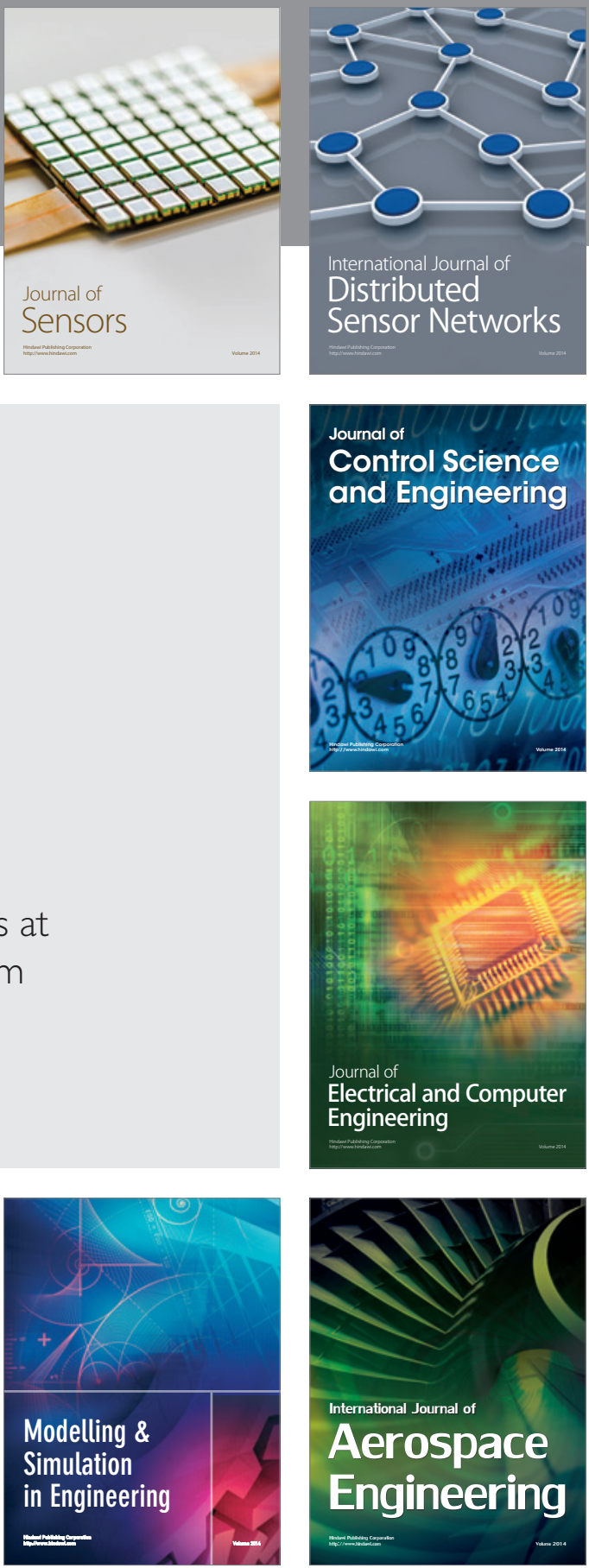

Journal of

Control Science

and Engineering
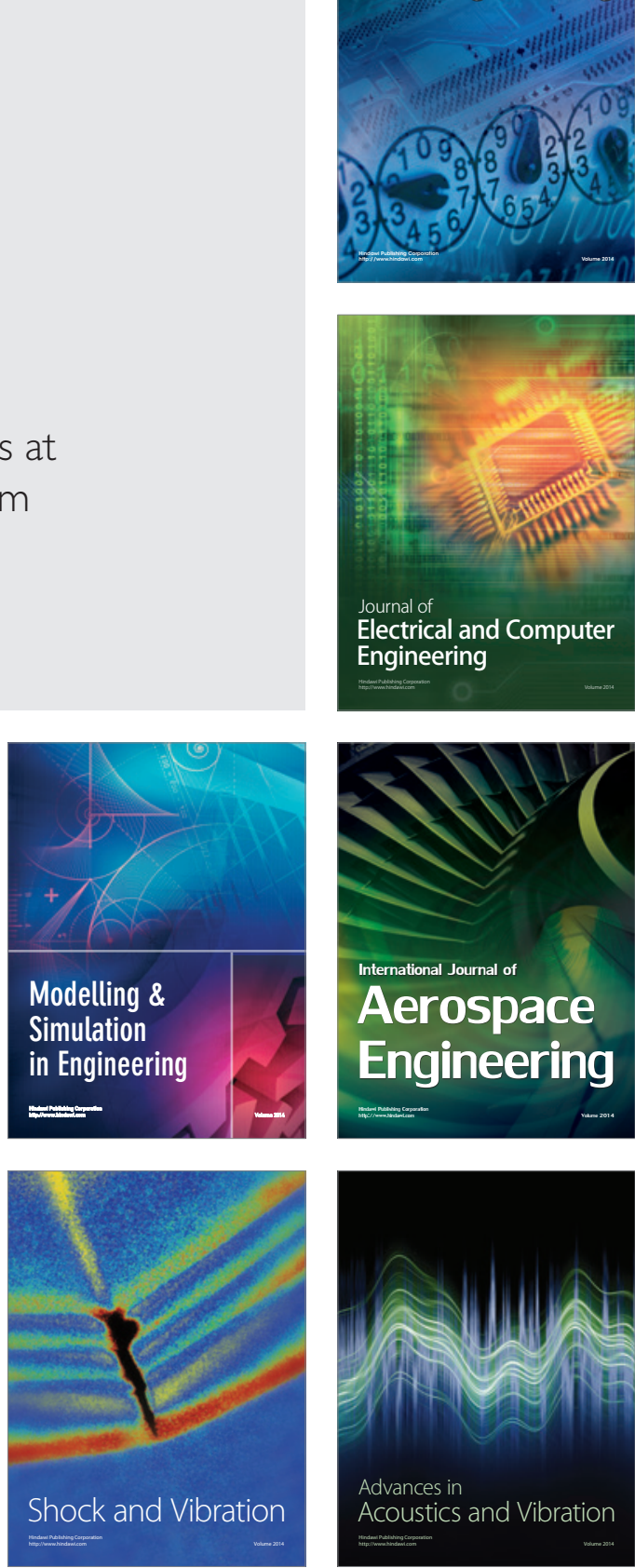